ORIGINAL ARTICLE

\title{
Labelling and patient knowledge of dispensed drugs as quality indicators in primary care in Botswana
}

\section{E Boonstra, M Lindbaek, E Ngome, K Tshukudu, P Fugelli}

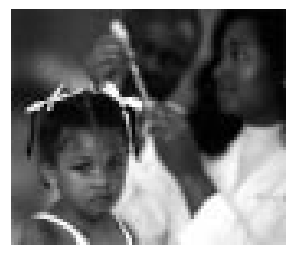

Objectives: To assess the quality of dispensing and patient knowledge of drugs dispensed in primary care in Botswana.

Setting: Thirty randomly assigned primary healthcare facilities in three districts of Botswana.

Participants: Patients visiting clinics and health posts.

Design: Analysis of data from prospective participative observations of the drug dispensing process and interview of patients about their knowledge of drugs received immediately after dispensing. The quality of drug labelling was assessed by calculating mean labelling scores composed of five dispensing attributes: name of patient, and name, strength, dosage, and volume of the drug (incorrect or no labelling=0, 1 point for each correct labelling attribute; maximum score=5). Mean knowledge scores were obtained immediately after dispensing from patient recall of name and dosage of drug, duration of treatment, and reason for prescription (incorrect recall=0, 1 point for each correct recall attribute; maximum score $=4$ ).

Results: 2994 consecutive patient consultations were analysed. The mean labelling score was 2.75 . Family welfare educators and pharmacy technicians scored highest (3.15 and 2.98, respectively) and untrained staff lowest (2.60). Factors independently associated with the labelling score were analgesics $v$ other drugs, district, health posts $v$ clinics, education of prescriber (nurse best), and years of

See end of article for authors' affiliations

Correspondence to:

Dr E Boonstra,

PO Box 123

6988 Askvoll, Norway;

boonstra@online.no

Accepted for publication 19 February 2003 experience of prescriber (4-11 years best). The mean patient knowledge score was 2.50 . The reason for prescription of the drug(s), dosage, duration of treatment, and name of the drug(s) was recalled by $92 \%, 83 \%, 44 \%$, and $31 \%$ of patients, respectively. The qualification level of the dispenser was the strongest factor independently associated with the knowledge score. Antibiotics had the second lowest score, both for labelling (2.39) and patient knowledge (2.39).

Conclusion: Only trained dispensing staff provided satisfactory quality of labelling. Patients had a fair knowledge of the drugs dispensed. The knowledge of drugs dispensed by family welfare educators was less than satisfactory. The labelling score is a useful indicator of the quality of dispensing, and the knowledge score of both the quality of prescribing and of dispensing. These indicators should be added to the WHO list of patient care indicators.

R ational prescription and use of drugs has been a concern in both developed and developing countries during the last two decades and has been promoted by WHO and others. ${ }^{1-4}$ Within drug use programmes, efforts have often been concentrated on ensuring rational prescribing habits, and the quality of dispensing and patient knowledge of drugs has been overlooked. ${ }^{4-6}$ Dispensing - that is, the process of preparing and handing out medicine to a named person on the basis of a prescription-requires the correct interpretation of the wishes of the prescriber and the accurate preparation and labelling of medicine for use by the patient as advised. Any error or failure in the dispensing process can jeopardise the care of the patient. ${ }^{6}$

One of the essential prerequisites for patient compliance is good patient knowledge of the medicines prescribed. Although the consulting nurse is the main source of information about drugs prescribed in Botswana primary care, the dispenser is in a position to reinforce patient knowledge about the drugs dispensed. The quality of labelling applied by dispensers, the time spent informing the patients, and the communication skills of the dispenser can therefore affect compliance rates. ${ }^{7-10}$

In studies on the quality of drug prescription in rural health centres in Burkina Faso, only 33\% of the patients received information on the duration of the treatment and $68 \%$ of the patients could recall the correct dosage of the drugs prescribed. ${ }^{11}$ Lebitsa et $a l^{12}$ found that only $11 \%$ and $21 \%$ of drugs dispensed at clinics and health posts, respectively, in Botswana had been adequately labelled, and sufficient knowledge about the drugs had been obtained by $56 \%$ and $57 \%$ of patients, respectively. This study concluded that, while the patterns of drug use in Botswana were not very different from those in other developing countries, a major problem exists with the dispensing process.

Botswana provides comprehensive public primary health care services to the majority of its population. Most of the curative and preventive healthcare services are organised and provided by trained staff, as is the case in rural areas of many other African countries. Health posts, which represent the lowest level of institutional primary health care, are supervised by clinics which provide more comprehensive services and are better staffed. The Botswana government, through the Ministry of Health, has committed itself to achieving quality in health care. It has adopted a strategy for total quality management as a principle in health care, and has formulated a vision to provide a health service which inspires confidence in users and gives job satisfaction to health workers. Optimal drug utilisation-providing the best treatment at the lowest cost-is one of its priorities.

Since the mid 1960s nurses in Botswana have prescribed drugs at primary healthcare facilities according to national standards. ${ }^{13}$ While drugs are only prescribed by trained health workers, dispensing of drugs is carried out by both trained and untrained staff. Trained health workers include nurses, pharmacy technicians, and family welfare educators; nontrained health workers comprise secondary school leavers 
Table 1 Structure of healthcare personnel involved in prescribing and dispensing of drugs in Botswana primary care by training level and main function

\begin{tabular}{|c|c|c|c|c|}
\hline $\begin{array}{l}\text { Type of healthcare worker } \\
\text { according to qualification }\end{array}$ & $\begin{array}{l}\text { No of years } \\
\text { training }\end{array}$ & Main function & Prescribing & Dispensing \\
\hline \multicolumn{5}{|l|}{ Trained personnel } \\
\hline Family nurse practitioner & 5 & Curative work, deliveries, ANC, FP, MCH & Yes & Only when staff shortage \\
\hline General nurse/midwife & 4 & Curative work, deliveries, ANC, FP, MCH & Yes & Only when staff shortage \\
\hline General nurse & 3 & Curative work, deliveries, $\mathrm{FP}, \mathrm{MCH}$ & Yes & Only when staff shortage \\
\hline Enrolled nurse & 2 & Curative work, deliveries, FP, MCH & Yes & Yes \\
\hline Student nurse & 2 & Curative work, deliveries, FP, MCH & Yes & Yes \\
\hline Pharmacy technician & 3 & Drug management including supervision & No & Yes \\
\hline Family welfare educator & 0.25 & $\begin{array}{l}\text { Health promotion and prevention in the community, } \\
\text { some clinical duties at the health facility }\end{array}$ & No & Yes \\
\hline \multicolumn{5}{|l|}{ Untrained personnel } \\
\hline Tirelo Sechaba participant* & None & Assisting with general duties & No & Yes \\
\hline Nurse orderly $\dagger$ & None & Assisting with general duties & No & Yes \\
\hline General duty assistant $\ddagger$ & None & Cleaning and general duties & No & Only when staff shortage \\
\hline
\end{tabular}

$\mathrm{ANC}=$ antenatal clinic; $\mathrm{FP}=$ family planning; $\mathrm{MCH}=$ mother and child health care

* Tirelo Sechaba participants=secondary school leavers who are obliged to work 1 year within the public sector, including the health sector.

$\dagger$ Nurse orderlies assist the general nurses and relieve them from general duties.

$\ddagger$ General duty assistants normally have primary school education.

who are obliged to work 1 year in the public sector, nurse orderlies, and general duty assistants (table 1). Literacy is a prerequisite for anyone taking on this role. In general, all auxiliary health workers in Botswana have primary school education. However, doubts have been raised as to whether untrained health staff should participate in the dispensing of medicines.

Among a standard set of core drug use indicators developed by $\mathrm{WHO}^{7}$ the following measures of the quality of dispensing are listed: mean dispensing time, percentage of drugs actually dispensed, and percentage of drugs adequately labelled. As a measure of patient knowledge, only knowledge of the correct dosage has been used. To our knowledge, no measures of the quality of labelling and patient knowledge of dispensed drugs are available.

This study is part of a larger drug utilisation study in primary health care in Botswana focusing on the quality of the diagnostic process, the quality of pharmacotherapeutic decision making, ${ }^{14}$ the quality of dispensing, and logistics related to drug utilisation. Work on the quality of nurses' diagnostic skills, the quality of syndromic management of sexually transmitted diseases, and on the quality of child care in relation to the management of respiratory tract infections and diarrhoea is also ongoing. This study will form the basis for the evaluation of possible intervention studies in the second phase of the project.

The aims of this study were (1) to assess the quality of labelling in relation to the level of training of dispensing personnel; (2) to assess patient knowledge of the drugs dispensed according to the level of training of prescribing and dispensing staff; and (3) to compare WHO core drug dispensing indicators ${ }^{8}$ between districts and types of health facility.

\section{METHODS}

\section{Design of the study}

This study is part of a larger drug utilisation study, designed as a prospective participatory study, the methods of which have been described in detail elsewhere. ' Briefly, the study consisted of 2994 consecutive consultations at 30 primary healthcare facilities in three of the 22 administrative districts of Botswana ( 1000 consultations per district) from June to November 1998. The districts were chosen as being representative of Botswana primary care, with one rural district (Kgalagadi North), one urban district (Gaborone), and one rural/urban district (Ngami/Maun). ${ }^{15}$ In each of the districts 10 health facilities were randomly chosen, consisting of two clinics and eight health posts in Ngami and Kgalagadi North
Box 1 Inclusion and exclusion criteria

Inclusion criteria

- All consultations, both first visits and repeats

- Oral consent by the patient for participation in the study or, in the case of children, by the parent

Exclusion criteria

- Healthy children undergoing weight control or vaccination

- Healthy children attending for antenatal care or family planning

- Patients undergoing direct observed treatment (DOT) of tuberculosis

while in Gaborone only clinics were included. The total number of consultations in each of the facilities was relative to the number of outpatient attendances for 1996. Details on inclusion/exclusion criteria are shown in box 1 .

In clinics dispensing is normally carried out by a nurse, pharmacy technician, or by untrained staff, while at health posts family welfare educators or untrained personnel dispense drugs.

\section{Participatory observation}

Participatory observation can be defined as a process of collecting essential information about a process such as a consultation or dispensing by active or passive participation. In our survey the consultations were observed without active participation by the research team which consisted of two nurses/midwives and a pharmacy technician. To minimise observer bias, all observers were instructed not to interfere with the consultations or dispensing process. The pharmacy technician recorded the time which the patient spent at the dispensing counter (total dispensing time) and the time during which the patient was informed about the dispensed medicines (dispensing counselling time).

In order to reduce observer bias, the health facilities were not informed about the survey and schedule of the team. The nurse in charge of the health facility informed the patients in the waiting room about the survey in general terms, eliciting their consent to participate.

\section{Calculation of scores}

The quality of labelling was recorded by assigning a score to each of five essential dispensing quality attributes: name of patient and name, strength, dosage and volume of the drug. Correct labelling was given a score of 1 per attribute and 
Table 2 Quality of labelling of drugs dispensed in Botswana primary care by district and health facility

\begin{tabular}{|c|c|c|c|c|c|c|c|}
\hline & \multicolumn{3}{|l|}{ District } & \multicolumn{3}{|l|}{ Health facility } & \multirow[b]{2}{*}{$\begin{array}{l}\text { Statistical } \\
\text { significance }\end{array}$} \\
\hline & $\begin{array}{l}\text { Ngami } \\
(n=1000 ; \\
N=2137)\end{array}$ & $\begin{array}{l}\text { Gaborone } \\
(n=997 \\
N=2097)\end{array}$ & $\begin{array}{l}\text { Kgalagadi } \\
(n=997 ; \\
N=2227)\end{array}$ & $\begin{array}{l}\text { Clinics } \\
(n=2000 ; \\
N=4209)\end{array}$ & $\begin{array}{l}\text { Health posts } \\
(n=994 ; \\
N=2252)\end{array}$ & $\begin{array}{l}\text { Total } \\
(n=2994 ; \\
N=6461)\end{array}$ & \\
\hline Dosage of drug & $1613(75)$ & $1579(75)$ & 1758 (79) & 3239 (74) & $1711(81)$ & 4950 (77) & \\
\hline Name of drug & 1460 (68) & $1463(70)$ & $1784(80)$ & $3150(72)$ & 1557 (74) & 4707 (73) & $2 * * 3 * *$ \\
\hline Strength of drug & $875(41)$ & $1262(60)$ & $1125(51)$ & $2358(54)$ & 904 (43) & $3262(50)$ & $1 * * 2 * * 3 * * 4 * *$ \\
\hline Name of patient & $897(42)$ & $868(41)$ & $1163(52)$ & 1607 (37) & $1222(58)$ & 2829 (44) & $2 * * 3 * * 4 * *$ \\
\hline Volume of drug & $190(9)$ & $546(26)$ & 1317 (59) & 1432 (33) & 621 (29) & 2053 (32) & $1 * * 2 * * 3 * * 4 * *$ \\
\hline $\begin{array}{l}\text { Mean }(95 \% \mathrm{Cl}) \\
\text { labelling scoref }\end{array}$ & $\begin{array}{c}2.61 \\
(2.55 \text { to } 2.68)\end{array}$ & $\begin{array}{l}2.80 \\
(2.74 \text { to } 2.87)\end{array}$ & $\begin{array}{c}2.82 \\
(2.76 \text { to } 2.89)\end{array}$ & $\begin{array}{c}2.69 \\
(2.65 \text { to } 2.74)\end{array}$ & $\begin{array}{c}2.86 \\
(2.79 \text { to } 2.92)\end{array}$ & $\begin{array}{c}2.75 \\
(2.71 \text { to } 2.78)\end{array}$ & \\
\hline
\end{tabular}

Values are number $(\%)$.

$\mathrm{N}=6461$ dispensed drugs with information on labelling score; $\mathrm{N}_{1}=6929$ prescribed drugs; $\mathrm{n}=2994$ patients.

†Statistical significance: $1=N$ gami-Gaborone, $2=$ Gaborone-Kgalagadi, $3=$ Ngami-Kgalagadi, $4=c l i n i c s /$ health posts; ${ }^{*} p<0.01$, * $p<0.001$.

$\ddagger A$ maximum score of 5 could be obtained.

incorrect or no labelling was scored 0 , and the total dispensing score for each drug was calculated (maximum total score of 5 per drug dispensed). Dispensing indicators were calculated by district and type of health facility. A score of 2.70 and above was regarded as a satisfactory quality of labelling, representing $54 \%$ of the total score.

Patients' knowledge of the drugs dispensed was registered by a second survey team nurse who assessed their recall of the name of the drug, dosage, duration of treatment, and reason for prescription. For each of the attributes a correct answer was assigned a score of 1 and an incorrect answer 0. For each drug the total knowledge score was calculated (maximum knowledge score of 4 per drug). The mean knowledge score by group of drugs ${ }^{15}$ was calculated; a score of 2.40 and above was regarded as a satisfactory level of knowledge, representing $60 \%$ of the total score.

\section{Data analysis}

All data were entered into EPI Info 6 and SPSS 9.0. In the statistical analysis a $\chi^{2}$ test was used for frequencies and the Student's $t$ test for mean values. The level of significance in the bivariate analyses was set at 0.01 because of multiple testing. To assess how knowledge and dispensing scores as dependent variables were affected by independent variables, linear regression was performed. The regression coefficient B was used to express the change in knowledge or dispensing score for one unit of the numerical value of the independent variable, according to the regression equation for a multivariate linear regression $\left(y=a+b_{1} x_{1}+b_{2} x_{2}+\ldots b_{n} x_{n}+e\right)$.

Only factors with a $\mathrm{p}$ value of $<0.20$ in the bivariate analysis were included in the linear regression analysis.

\section{RESULTS}

A total of 2994 consultations were included: 1000 in Ngami East (range 9-321 per health facility), 997 in Gaborone (range 19-179), and 997 in Kgalagadi North (range 10-367); 1240 $(41 \%)$ were male and 1754 (59\%) were female. The number of consultations according to patient age was: $<5$ years, 539 (18\%); 5-14 years, 373 (12\%); 15-49 years, 1736 (58\%); and $>50$ years, $346(12 \%)$. For the country as a whole the proportions in the four age groups were $15 \%, 26 \%, 49 \%$, and $10 \%$,

Table 3 Mean patient labelling and knowledge scores according to group of drugs dispensed in Botswana primary care and by level of education in dispensing and prescribing staff

\begin{tabular}{|c|c|c|c|}
\hline & $\mathrm{N}(\%)$ & $\begin{array}{l}\text { Mean labelling score* } \\
(95 \% \mathrm{Cl})\end{array}$ & $\begin{array}{l}\text { Mean knowledge score ** } \\
(95 \% \mathrm{CI})\end{array}$ \\
\hline \multicolumn{4}{|l|}{ Drug group } \\
\hline Analgesic & $1898(29)$ & 3.07 (3.01 to 3.14$)$ & 2.58 (2.54 to 2.63$)$ \\
\hline Neuroleptic & $221(3)$ & 3.00 (2.78 to 3.22$)$ & $2.30(2.17$ to 2.43$)$ \\
\hline $\mathrm{Gl}$ tract and metabolism & $1319(20)$ & 2.72 (2.64 to 2.80 ) & 2.53 (2.47 to 2.58$)$ \\
\hline Antibacterial & 1069 (17) & 2.39 (2.28 to 2.49$)$ & 2.39 (2.33 to 2.45$)$ \\
\hline Dermatological & $374(6)$ & 2.04 (1.89 to 2.19$)$ & 2.47 (2.37 to 2.57$)$ \\
\hline Anti-inflammatory & $623(10)$ & 2.77 (2.65 to 2.88 ) & 2.43 (2.35 to 2.51$)$ \\
\hline Respiratory & $292(5)$ & 2.83 (2.66 to 3.00$)$ & 2.60 (2.49 to 2.70$)$ \\
\hline Cardiovascular & 218 (3) & 3.26 (3.07 to 3.45$)$ & 2.67 (2.53 to 2.82$)$ \\
\hline Antiparasitic & $131(2)$ & 2.53 (2.28 to 2.78$)$ & 2.41 (2.26 to 2.57$)$ \\
\hline Other & $316(5)$ & 2.42 (2.23 to 2.62$)$ & 2.44 (2.32 to 2.57$)$ \\
\hline Total & $6461(100)$ & 2.75 (2.71 to 2.79$)$ & 2.50 (2.48 to 2.53$)$ \\
\hline \multicolumn{4}{|l|}{ Dispensing staff } \\
\hline Nurses/pharmacy technicians & $2710(42)$ & 2.77 (2.71 to 2.83 ) & 2.81 (2.77 to 2.84$)$ \\
\hline Family welfare educators & 902 (14) & 3.15 (3.05 to 3.24$)$ & $2.39(2.33$ to 2.46$)$ \\
\hline Untrained staff & 2849 (44) & 2.60 (2.55 to 2.66$)$ & 2.25 (2.21 to 2.28$)$ \\
\hline Total & $6461(100)$ & $2.75(2.71$ to 2.78$)$ & 2.50 (2.48 to 2.53$)$ \\
\hline \multicolumn{4}{|l|}{ Prescribing staff } \\
\hline Nursing staff & $5397(84)$ & 2.78 (2.74 to 2.83 ) & 2.51 (2.48 to 2.52$)$ \\
\hline Enrolled nurses & $806(12)$ & 2.46 (2.36 to 2.57$)$ & 2.59 (2.52 to 2.65$)$ \\
\hline Family welfare educators & $258(4)$ & 2.85 (2.68 to 3.04 ) & 2.12 (2.04 to 2.71$)$ \\
\hline Total & $6461(100)$ & 2.75 (2.71 to 2.78$)$ & 2.50 (2.48 to 2.53$)$ \\
\hline
\end{tabular}

$\mathrm{N}=6461$ dispensed drugs with information on labelling score; $N_{1}=6929$ prescribed drugs; $n=2994$ patients. *A maximum score of 5 could be obtained.

${ }^{* *}$ A maximum score of 4 could be obtained. 


\begin{tabular}{|c|c|c|c|c|}
\hline $\begin{array}{l}\text { Factors independently associated } \\
\text { with labelling score }\end{array}$ & No of drugs & $\begin{array}{l}\text { Unstandardised coefficient } \\
\mathrm{B}+(95 \% \mathrm{Cl})\end{array}$ & $t$ value & $\mathrm{p}$ value \\
\hline \multicolumn{5}{|l|}{ Diagnosis } \\
\hline Not specified (reference) & 1935 & 0.00 & & \\
\hline Specified & 4526 & 0.14 (0.06 to 0.24$)$ & 3.43 & 0.001 \\
\hline \multicolumn{5}{|l|}{ Prescriber qualification } \\
\hline Not nurse (reference) & 1064 & 0.00 & & \\
\hline Nurse & 5397 & $0.37(0.26$ to 0.48$)$ & 6.70 & 0.0001 \\
\hline \multicolumn{5}{|l|}{ Prescribers' practice } \\
\hline$>11$ years (reference) & 2216 & 0.00 & & \\
\hline $4-11$ years & 2096 & $0.27(0.17$ to 0.36$)$ & 5.60 & 0.0001 \\
\hline $0-3$ years & 2149 & 0.10 (0.03 to 0.19 ) & 2.17 & 0.03 \\
\hline \multicolumn{5}{|l|}{ Patient factors (age and sex) } \\
\hline $0-15$ years (reference) & 1854 & 0.00 & & \\
\hline $16-31$ years & 2165 & 0.11 (0.01 to 0.20$)$ & 2.23 & 0.03 \\
\hline$>31$ years & 2442 & 0.14 (0.04 to 0.24$)$ & 2.99 & 0.003 \\
\hline Male (reference) & 2560 & 0.00 & & \\
\hline Female & 3901 & $0.19(0.11$ to 0.26$)$ & 4.95 & 0.0001 \\
\hline \multicolumn{5}{|l|}{ Drug factors } \\
\hline Other factors (reference) & 4298 & 0.00 & & \\
\hline Analgesics & 2163 & 0.57 (0.49 to 0.65$)$ & 14.41 & 0.0001 \\
\hline \multicolumn{5}{|l|}{ Health facility } \\
\hline Clinic (reference) & 4209 & 0.00 & & \\
\hline Health post & 2252 & 0.47 (0.37 to 0.57$)$ & 9.41 & 0.0001 \\
\hline \multicolumn{5}{|l|}{ Health district } \\
\hline Ngami (reference) & 2137 & 0.00 & & \\
\hline Kgalagadi & 2227 & 0.98 (0.88 to 1.08$)$ & 11.58 & 0.0001 \\
\hline Gaborone & 2097 & 1.02 (0.85 to 1.20$)$ & 19.17 & 0.0001 \\
\hline
\end{tabular}

respectively. ${ }^{17}$ The mean age was 25.5 years; $91 \%$ of all consultations were first consultations.

A total of 104 health staff carried out the dispensing, comprising the following groups: two family nurse practitioners $(0.1 \%), 535$ registered nurses $(18 \%), 318$ enrolled nurses (11\%), 430 pharmacy technicians (14\%), 404 family welfare educators (14\%), and 1305 untrained staff $(44 \%)$. At clinics $(n=2000)$ the figures for the different groups were one $(0.1 \%)$, $440(22 \%), 299(15 \%), 430(22 \%), 108(5 \%)$, and $722(36 \%)$, respectively, and at health posts $(n=994)$ one $(0.1 \%), 95$ (10\%), 19 (2\%), 0 (0\%), 296 (30\%), and 583 (59\%), respectively.

Gaborone had the highest proportion of trained dispensing staff $(99.8 \%)$, Ngami district the lowest $(21 \%)$, and in Kgalagadi district the proportion was $48 \%$.

Nine hundred and five (30\%) of all diagnoses were non-specific symptom diagnoses categorised as "signs, symptoms and ill defined conditions". The most frequent conditions diagnosed were respiratory diseases (613 (21\%)), sexually transmitted diseases $(224(8 \%))$, skin diseases (59 $(7 \%))$, injuries (206 (7\%)), and diarrhoea (156(5\%)).

The main drugs prescribed were analgesics (2009 (29\%)), antibiotics $(1116(16 \%))$, vitamins (933 (14\%)), antiinflammatory drugs $(672(10 \%))$, and dermatological preparations $(407(6 \%))$, comprising $75 \%$ of all prescriptions. ${ }^{15}$

\section{Quality of labelling of drugs}

Table 2 shows the quality of the labelling of drugs according to district and health facility. The dosage, name, strength, and volume of the drug was written on the label in 4950 (77\%), $4707(73 \%), 3262(50 \%)$ and $2053(32 \%)$ cases, respectively, and the name of the patient in 2829 (44\%). The mean labelling score was 2.75 ( $95 \%$ CI 2.71 to 2.78 ).

Table 3 shows the mean labelling score by main group of drugs. It was highest for cardiovascular drugs (3.26), analgesics (3.07), neuroleptics (3.00), drugs for the respiratory system (2.83), and for the alimentary tract (2.72). The mean labelling score and mean knowledge score are also shown according to the level of training of the dispensing and prescribing staff. Only nurse orderlies and general duty assistants achieved less than satisfactory mean dispensing scores. Untrained staff and family welfare educators had knowledge scores that were below the satisfactory level (2.25 and 2.39, respectively). Untrained prescribing staff (family welfare educators) scored significantly lower (2.12) than trained health staff.

Table 4 shows the factors which were found to be independently associated with the labelling score by multivariate linear regression analysis. The strongest factors were analgesics compared with other drugs, district, health posts compared with clinics, education of prescriber (nurse best), and years of experience of prescriber (4-11 years best). The explained variance was $11 \%$.

\section{Patient knowledge of drugs dispensed}

Table 5 shows patient knowledge of drugs dispensed and the mean knowledge score by district and health facility. The mean knowledge score was 2.50. The reason for the drug prescription was recalled in 5973 (92\%), dosage in 5354 (83\%), duration of treatment in 2865 (44\%), and name of the drug(s) in $1982(31 \%)$ of the drugs dispensed. With respect to dosage, duration of treatment and name of drugs, clinics scored significantly higher than health posts, and Gaborone district scored significantly higher than Ngami and Kgalagadi districts. The mean knowledge score varied with age with the highest score in patients aged 16-31 years (2.65 (95\% CI 2.61 to 2.69)). The score for those aged 32 years and above was 2.31 (95\% CI 2.27 to 2.35 ).

\section{Independent predictors of knowledge score}

Table 6 shows the factors which were found to be independently associated with the knowledge score by linear regression analysis. The strongest factor was the level of qualification of the dispenser $(p=0.0001)$, which gave a difference of $20 \%$ compared with the mean knowledge score. A high labelling score and less than three drugs dispensed were also 
Table 5 Patient knowledge of drugs dispensed drugs in primary care in Botswana by district and health facility

\begin{tabular}{|c|c|c|c|c|c|c|c|}
\hline & \multicolumn{3}{|l|}{ District } & \multicolumn{3}{|l|}{ Health facility } & \multirow[b]{2}{*}{$\begin{array}{l}\text { Statistical } \\
\text { significance }\end{array}$} \\
\hline & $\begin{array}{l}\text { Ngami } \\
(n=1000 ; \\
N=2137)\end{array}$ & $\begin{array}{l}\text { Gaborone } \\
(n=997 \\
N=2097)\end{array}$ & $\begin{array}{l}\text { Kgalagadi } \\
(n=997 ; \\
\mathrm{N}=2227)\end{array}$ & $\begin{array}{l}\text { Clinics } \\
(n=2000 ; \\
N=4209)\end{array}$ & $\begin{array}{l}\text { Health posts } \\
(n=994 ; \\
\mathrm{N}=2252)\end{array}$ & $\begin{array}{l}\text { Total } \\
(n=2994 ; \\
N=6461)\end{array}$ & \\
\hline Reason for prescription & $1932(90)$ & $2011(96)$ & 2030 (91) & $4024(96)$ & 1949 (87) & $5973(92)$ & $4^{*}$ \\
\hline Dosage of prescription & $1717(80)$ & $1841(88)$ & 1796 (81) & 3660 (87) & $1694(75)$ & $5354(83)$ & $4 * *$ \\
\hline Number of days & 682 (32) & 1245 (59) & 992 (45) & $2148(51)$ & 717 (32) & 2865 (44) & $1 * * 2 * * 3 * * 4 * *$ \\
\hline Name of drug & $504(24)$ & 923 (44) & $555(25)$ & $1488(35)$ & $494(22)$ & $1982(31)$ & $1 * * 1 * * 4^{* *}$ \\
\hline $\begin{array}{l}\text { Mean knowledge } \\
\text { score }(95 \% \mathrm{Cl}) \ddagger\end{array}$ & $\begin{array}{c}2.24 \\
(2.20 \text { to } 2.28)\end{array}$ & $\begin{array}{c}2.87 \\
(2.82 \text { to } 2.91)\end{array}$ & $\begin{array}{c}2.41 \\
(2.37 \text { to } 2.45)\end{array}$ & $\begin{array}{c}2.59 \\
(2.56 \text { to } 2.63)\end{array}$ & $\begin{array}{c}2.33 \\
(2.29 \text { to } 2.37)\end{array}$ & $\begin{array}{c}2.50 \\
(2.48 \text { to } 2.53)\end{array}$ & \\
\hline
\end{tabular}

Values are number (\%).

$\mathrm{N}=6461$ dispensed drugs with information on labelling score; $N_{1}=6929$ prescribed drugs; $n=2994$ patients.

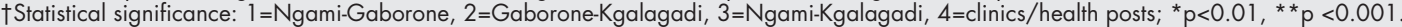

$\ddagger$ A maximum score of 4 could be obtained.

significantly associated with the knowledge score, giving a difference that was clinically significant. The explained variance was $16 \%$.

\section{Core dispensing indicators}

Table 7 shows the core dispensing indicators. The mean total dispensing time and dispensing counselling time was significantly higher for health posts (133 and 27 seconds, respectively) than for clinics ( 108 and 23 seconds, respectively; $\mathrm{p}<0.01$ for both). The mean dispensing time was significantly higher in the Ngami district (147 seconds) than in the Gaborone (88 seconds) and Kgalagadi districts ( 113 seconds).

\section{DISCUSSION}

This study has shown that only trained dispensing staff provided a satisfactory quality of drug labelling and imparted a satisfactory level of knowledge of the dispensed drugs to the patients. Only trained staff achieved satisfactory mean knowledge scores, presumably as a result of better information given by the trained dispenser. Patients generally had a fair knowledge of drugs dispensed. We believe that the level of training of prescribers is one of the main determinants of patient knowledge of drugs, and this is supported by our finding that family welfare educators had lower than satisfactory scores for patient knowledge of drugs dispensed. This is to be expected as this group of health workers only has a short training in preventive health and only in exceptional cases are they used as clinicians. The second lowest labelling and patient knowledge scores occurred with antibiotics. In assessing the quality of dispensing and prescribing, both labelling and patient knowledge scores were found to be useful indicators of patient care.

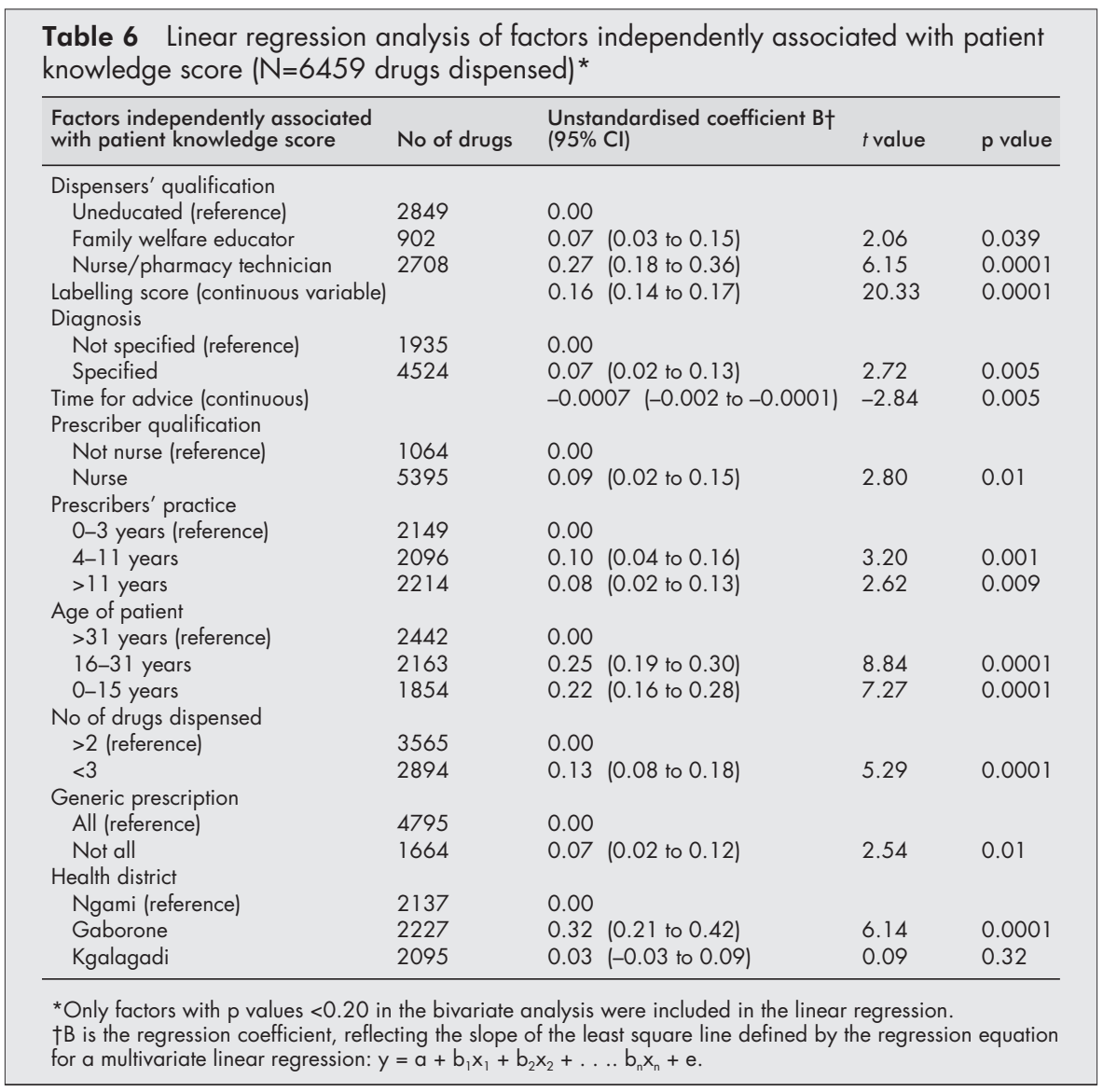




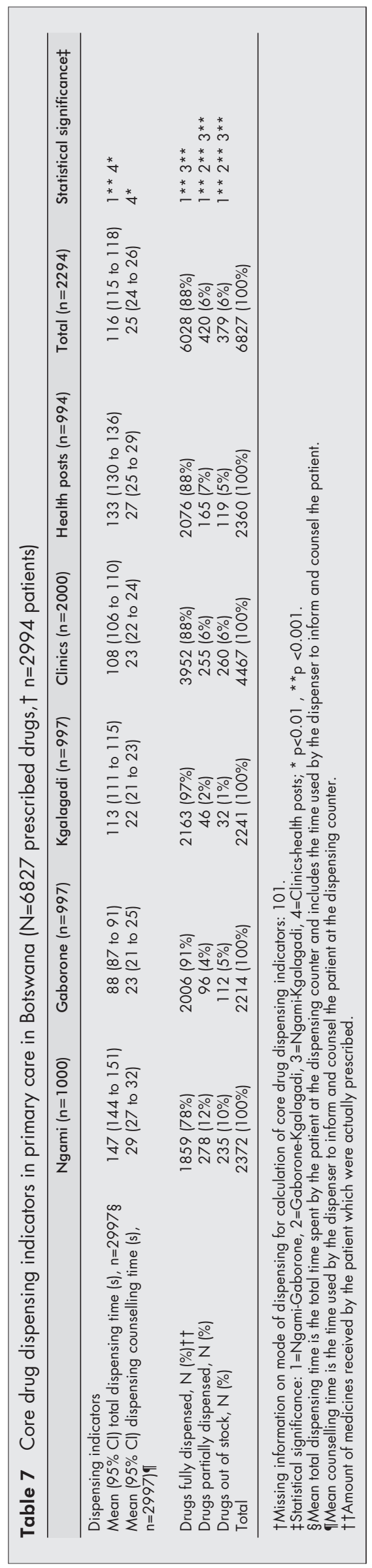

\section{Limitations of the study}

The main limitation of this prospective study is the risk of observer bias. Some of the health facilities may have heard rumours about the ongoing survey, anticipating a possible visit by the research team. This may have resulted in a more favourable outcome than otherwise would have been the case. We also cannot exclude the possibility that the participative research process in itself may have contributed to improving the quality of health care provided. Observer bias was minimised by the visits of the team being unannounced, and during the consultations and dispensing there was no interference by the survey team workers.

The distribution of clinics and health posts differed widely between Gaborone, a district which only has clinics, and Ngami and Kgalagadi districts which each have two clinics and eight health posts; only these latter two districts are therefore assumed to be comparable. However, the high degree of similarity in age distribution and morbidity pattern among the respondents and in the country as a whole ${ }^{17}$ support our belief that the study is representative of primary health care in Botswana. We also believe that our findings probably also apply to many other countries in sub-Saharan Africa, at least in the rural areas where nurses are the backbone of primary health care-working as clinicians and representing the first point of contact for patients.

We have given each of the five labelling and the four knowledge features equal weighting because we regard them as equally important prerequisites for patient compliance. We did not find other studies where these features have been weighted.

\section{Quality of dispensing}

The labelling of the packages with the dosage and name of the drug by the dispensing staff was good, but the name of the patient was only written on the label in $50 \%$ of cases or less. The quality of dispensing is likely to be affected by the level of training of the dispensing staff. That family welfare educators, who are not specifically trained in dispensing drugs, achieved the highest mean labelling scores can be explained by the fact that they often spend most of their active working life in the village which nominated them for training; this arrangement assures continuity of care and enhances accountability. Regarded as Botswana's "barefoot doctors", they enjoy the trust of the communities they serve.

Linear regression analysis showed that a number of factors are independently associated with a high labelling score, but the explained variance is only $11 \%$ which indicates that other important factors may be present which have not been investigated. Both the district and health post/clinics were independently associated. It is interesting that analgesics had a significantly higher score than other drug groups, probably because the dispensers are familiar with them.

\section{Patient knowledge of drugs dispensed}

Patient knowledge is one of the essential prerequisites for patient compliance with treatment. Many factors determine patient knowledge, including the quality of the consultation and the information about the prescribed medicines given by the consulting health worker. The person dispensing the medicine is in a position to reinforce this information. This assumption was confirmed by our finding that the qualification of the dispenser appeared to be the strongest predictor of patient knowledge of drugs dispensed; the qualification of both the prescriber and the dispenser were strong predictors of patient knowledge of drugs received. However, family welfare educators who are not trained in clinical work achieved less than satisfactory patient knowledge scores compared with all trained consulting staff. This supports our belief that well trained clinicians are crucial for conveying essential information to the patient on drugs prescribed. However, the 
explained variance in patient knowledge scores is low, which suggests that other patient characteristics such as literacy may have an effect. The adult literacy rate for the period 1995-9 was $75 \%$ for women and $70 \%$ for men. ${ }^{18}$

During the consultation the nurse normally informs the patient about the diagnosis made and the medicine(s) prescribed. This may explain why patients scored highest on knowledge related to the reason for the prescription. Our findings of $83 \%$ and $44 \%$ recall of the correct dosage and duration of treatment compare favourably with those in Burkino Faso $^{10}$ of $68 \%$ and $33 \%$, respectively. The reason why patients score much lower on duration of treatment than on correct dosage can be explained by the fact that duration of treatment is often taken for granted as it is defined by the number of tablets dispensed and by the dosage.

Despite the fact that the mean consultation and dispensing counselling time was significantly shorter at clinics than at health posts, the mean knowledge score of drugs dispensed was significantly higher in patients at clinics than at health posts. ${ }^{1}$ This may be because the consulting and dispensing staff at clinics are better trained than those at health posts. However, Lebitsa et al $^{13}$ did not find any difference in the level of patient knowledge of drugs dispensed between clinics and health posts, which may be related to the use of other criteria. Patient knowledge was, however, found to be suboptimal (56\% and $57 \%$, respectively).

Our finding that patients' mean knowledge score was significantly lower in those in higher age groups may reflect differences in educational level and age related difficulties in memorising the information given. Relatively high knowledge scores were seen in respondents with a diagnosis of cardiovascular, respiratory tract, or digestive system disease. Drugs prescribed for cardiovascular diseases are mostly antihypertensives which are normally taken on a regular basis for a long time. Most of the drugs prescribed for digestive diseases were vitamins and mineral supplements which are drugs well known to patients. We compared recall rates for the name and dosage of dispensed cardiovascular medication in patients aged 60 years and older $(n=76)$ with recall rates from a study carried out by Cline et $a l^{19}$ in elderly patients of 70 years and above $(n=22)$. The name of the drug was correctly recalled by $16(21 \%)$ and $12(55 \%)$ patients, respectively, and the dosage was correctly recalled by 60 (79\%) and 11 (50\%), respectively. Although the studies are not fully comparable because of differing designs, the differences were not significant.

In our view, patients' knowledge of drugs dispensed is a useful indicator of the quality of prescribing and dispensing. It is relatively easy to measure and we consider that this indicator should be added to the existing list of indicators for patient care.

\section{Core dispensing indicators}

For some indicators of patient care the ideal value is obvious. Values for percentages of drugs actually dispensed $(88 \%$ in our survey), adequately labelled (the mean score of 2.75 in this survey represents $55 \%$ of the total score), and patient knowledge of the drug dispensed (the mean score of 2.50 represents $63 \%$ of the total score) should, of course, be as high as possible. Optimum values for dispensing time are more difficult to define. High values do not give much information, but low values may indicate a problem. Mean dispensing counselling time is a more interesting indicator than mean total dispensing time as it includes the time spent waiting at the counter. In a study from Nigeria the mean dispensing time per patient was extremely short ( 13 seconds). ${ }^{7}$ We regard the mean dispensing counselling time found in our survey ( 25 seconds) to be too short to allow for optimal information to be given on drugs and for answering questions from patients. There is therefore potential for improving patient knowledge scores by increasing counselling time during dispensing.

\section{Key messages}

- Only trained health staff provided satisfactory labelling of medicines; patients had a fair knowledge of drugs dispensed.

- Family welfare educators as prescribers were unsatisfactory in terms of patient knowledge of drugs dispensed, and should not be assigned clinical work involving prescribing drugs.

- Antibiotics had the second lowest scores for both labelling and patient knowledge.

- The major potential for quality improvement is in the training of primary healthcare providers.

- Treatment guides and training courses should emphasise the importance of correct labelling and instructions to patients when antibiotics are prescribed.

- Both labelling and patient knowledge scores are useful indicators for the assessment of the quality of dispensing and prescribing and should be added to the existing WHO list of patient care indicators.

- Intervention studies aimed at improving the quality of dispensing should be carried out using both scores.

\section{Implications for quality improvement}

Our findings indicate that the major potential for quality improvement is in the training of primary healthcare providers. This does not necessarily imply training to the highest level; family welfare educators with 3 months of formal training performed well. Within the available resources and existing level of training, the quality of prescribing and dispensing can probably be improved by giving priority to patients with a low level of knowledge of dispensed drugs, particularly older patients and those on neuroleptics. Special attention should be paid to instructing these patients properly, both in the consultation and in the dispensing process.

Ninety two percent of patients knew the reason for the prescription and $83 \%$ knew the dosage, but only $44 \%$ were aware of the duration of the medication. Antibiotics are among the most frequently prescribed drugs, but had the second lowest labelling and knowledge scores. Insufficient awareness of the duration of treatment may contribute to the increasing problem of bacteria resistant to antibiotics. Treatment guides and training courses should emphasise the importance of correct labelling and instructions to patients when antibiotics are prescribed.

\section{Future research}

Intervention studies need to be carried out using labelling and patient knowledge scores to assess improvements in weaknesses of dispensing. However, the technical and quantitative measurement of these parameters still leaves other essential questions unanswered. For example, (1) to what extent is labelled information and technical knowledge integrated into the patient's life; and (2) how are modern drugs perceived by patients who may still be in a transitional phase between traditional concepts of illness and healing and western biomedicine? Further qualitative research is needed to provide answers to these questions.

\section{ACKNOWLEDGEMENT}

The authors thank the nursing staff at the health facilities for their hospitality towards the field team and for their cooperation; the team of observers including the nurses Mrs Jessica Setswalo and Mrs Alice Kgwerepe for their dedication during the field work; Dr H V Hogerzeil, WHO Department of Essential Drugs and Medicine Policy, Geneva, and Professor Per Hjortdahl and Dr J Straand, Institute of General Practice and Community Medicine, University of Oslo for their valuable advice; and Associate Professor Håkon Gjessing for statistical advice. 


\section{Authors' affiliations}

E Boonstra, M Lindbaek, P Fugelli, Department of General Practice and Community Medicine, University of Oslo, Norway

E Ngome, Department of Population Studies, University of Botswana, Botswana

K Tshukudu, District Health Team, Ngami East District, Botswana

Funding: This study is part of the 1998 Botswana Drug Utilisation Study which is being carried out under a four year Health Sector Agreement between Norway (Institute of General Practice and Community Medicine, University of Oslo) and Botswana (Health Research Unit, Ministry of Health) on cooperation in health systems research. The study is financed jointly by both institutions.

\section{REFERENCES}

1 World Health Organization (WHO). Conference of experts on the rational use of drugs, Nairobi: report on the rational use of drugs. Geneva: WHO, 1987.

2 Laing RO. Rational drug use: an unsolved problem. Trop Doctor 1990;20:101-3.

3 Dukes MNG, ed. Drug utilization studies. Methods and uses. WHO Regional Publications, European Series No.45. Copenhagen: WHO Regional Office for Europe, 1993.

4 World Health Organization. Managing drug supply. 2nd ed. West Hartford, USA: Kumarian Press, 1997.

5 Rogers PJ, Rees JE. How community pharmacists label medicines prescribed without appropriate dosage instructions. J Soc Admin Pharmacy 1997;14(3).

6 Hogerzeil HV, Ross-Degnan BD, Laing RO, et al. Field tests for rational drug use in twelve developing countries. Lancet 1993;342:1408-10.
7 World Health Organization/Action Programme on Essential Drugs (WHO/DAP). How to investigate drug use in health facilities: selected drug use indicators. WHO/DAP/93.1. Geneva: WHO/DAP, 1993.

8 George CF. Telling patients about their medicines. BMU 1987;294: 1566-7.

9 Wilson $M$, Robinson EJ, Blenkinsopp A, et al. Customers' recall of information given in community pharmacies. Int J Pharm Pract 1992:1:152-9.

10 Krause G, Borchert M, Benzler J, et al. Rationality of drug prescriptions in rural health centres in Burkina Faso. Health Policy Planning 1999;14:291-8

11 Krause G, Borchert M, Benzler J, et al. Performance of village pharmacies and patient compliance after implementation of an essential drug programme in rural Burkina Faso. Health Policy Planning 1998;13:159-66.

12 Lebitsa OK, Kgattlwane J, Sebako V. Report on the Botswana drug use indicator study of 1997. Gaborone: Ministry of Health, 1997.

13 Anon. Botswana treatment guide 1992. Ministry of Health and National Standing Committee on Drugs, May 1991

14 Boonstra E, Lindbæk M, Khulumani $P$, et al. Adherence to treatment guidelines in primary health care facilities in Botswana. Trop Med Int Health 2002;7:178-86.

15 Khulumani $\mathbf{P}$, Lauglo $M$. The availability and distribution of resources for primary health care services. Gaborone: Ministry of Health, Health Research Unit, 1998.

16 WHO Collaborating Centre for Statistics Methodology. ATC classification and DDD assignment. WHO Collaborating Centre for Statistics Methodology, c/o Norsk Medisinaldepot AS, Oslo, 1996.

17 Central Statistic Office. Population projections January 1997 (based on Botswana National Census 1991). Gaborone: Central Statistics Office, 1991.

18 UNICEF. The state of the world's children 2001

19 Cline CM, Biorck-Linne AK, Israelsson BY, et al. Non-compliance and knowledge of prescribed medication in elderly patients with heart failure. Eur J Heart Failure 1999;1:145-9. 